\title{
Formulation and Evaluation of Delayed Release Pellets of Ivabradine Hydrochloride
}

\author{
Sanjesh G. Rathi*, Himanshu G. Parmar, Shrenik K. Shah, Sohansinh S. Vaghela \\ Department of Pharmaceutics, Saraswati Institute of Pharmaceutical Sciences, Dhanap. Gandinagar, Gujarat, India. \\ *Corresponding author's E-mail: rathi.sanjesh@gmail.com
}

Received: 06-05-2021; Revised: 24-06-2021; Accepted: 30-06-2021; Published on: 15-07-2021.

\begin{abstract}
The aim of preset research work is to formulate and evaluate delayed release pellets of Ivabradine $\mathrm{HCl}$. Pellets are prepared using extrusion-spheronization process and the process parameters are optimized. Polymer coating done with Kollicoat SR 30 D as rate controlling polymer and finally enteric coating done with Eudragit L30D-55. Drug release in formulation F1-F9 studied and it found that the low polymer concentration ( $2 \%$ ) was unable to retard the drug release up to $12 \mathrm{hr}$ so concentration increased batch by batch and finally $12 \%$ coating batch gives desired results which retard the drug release up to $12 \mathrm{hr}$. also found that the drug release was very low after more \% coating than the $12 \%$. Hence based on that the F5 batch was optimized batch and its found stable during stability study of 1 month.Delayed release pellets of Ivabradine $\mathrm{HCl}$ was successfully prepared using Kollicoat SR 30 D as rate controlling polymer.
\end{abstract}

Keywords: Ivabradine $\mathrm{HCl}$, Pellets, delayed release.

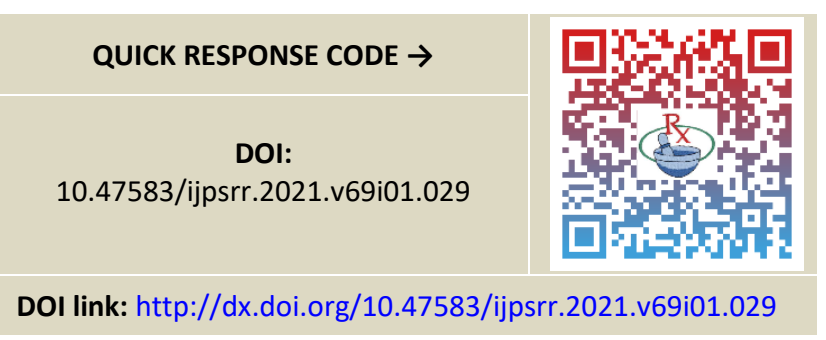

\section{INTRODUCTION}

ellets are agglomerates of fine powders or granules of mass medications and excipients. They comprise of little, free-streaming, circular or semi-round strong units, normally from around $0.5 \mathrm{~mm}$ to $1.5 \mathrm{~mm}$, and are proposed for the most part for oral organization. Inserts of little, clean chambers shaped by pressure from cured masses are additionally characterized as pellets in drug store. Pellets can be set up by numerous strategies, the compaction and medication layering procedures being the most generally utilized today. Despite which producing process is utilized, pellets need to meet the accompanying necessities; ${ }^{1}$

1. They ought to be circular and have a smooth surface; both considered ideal attributes for consequent film covering.

2. The molecule estimate range ought to be as tight as could reasonably be expected. The ideal size of pellets for pharmaceutical utilize is in the vicinity of 600 and $1000 \mathrm{am}$.

3. The pellets ought to contain however much as could reasonably be expected of the dynamic fixing to keep the span of the last measurements frame inside sensible breaking points.
The upside of various unit items as a controlled-discharge dose shape is accepted to be their conduct in vivo as a result of their worthwhile scattering design in the gastrointestinal tract and their uncommon size attributes. Gastro-intestinal travel time enormously influences the bioavailability of a medication from an orally regulated controlled discharge planning. Once the stomach had discharged, the circles started to travel in groups. It has been accounted for that pellets littler than around $2.4 \mathrm{~mm}$ in breadth, are free from the stomach related capacity of the stomach and the end arrangement of the pyloric sphincter to be discharged from the stomach. A greatest pellet width of $1.5 \mathrm{~mm}$ has been suggested for an ideal various unit plan plainly demonstrated that the edge measure must be beneath $1 \mathrm{~mm}$. As indicated by there is no real cut-off size for gastric discharging, however as the span of the pellets increment, unsurprising exhausting from the fed stomach winds up plainly dubious and profoundly factor. ${ }^{1}$

\section{Methods of Preparation Pellets ${ }^{2,3,4}$}

Compaction and medication layering are the most broadly utilized pelletization systems in pharmaceutical industry. Of the compaction systems, expulsion and Spheronization is the most well known technique. As of late, in any case, liquefy pelletization has been utilized much of the time in making compaction pellets utilizing an alternate sort of hardware, e.g. a high shear blender. Other pelletization techniques, for example, globulation, balling and pressure are likewise utilized as a part of the advancement of pharmaceutical pellets in spite of the fact that in a restricted scale. Following of the for the most part strategies utilized for the pelletization; 


\section{Extrusion-Spheronization ${ }^{3}$}

Expulsion Spheronization is a various advance compaction process involving dry blending of the fixings with excipients, wet granulation of the mass, expulsion of the wetted mass, charging the extrudates into the Spheronizer to create a circular shape, drying the wet pellets in a dryer and, at last, screening to accomplish the required size dissemination. The granulation step can be performed both in group sort processors, including a traditional planetary blender, and in vertical or even high-shear and sigma-cutting edge blenders, and in consistent blenders, and high-shear twin-screw blender extruder. Extruders for the expulsion procedure (step) have been grouped by and large as screw, strainer and wicker container, roll and slam extruders. In view of the sort of encourage component used to Transport the mass towards the kick the bucket, they have been comprehensively delegated screw, gravity or cylinder sort extruders. Most Spheronizer have been planned in view of a rotating notched plate driven by a variable-speed drive unit at the base of a smooth-walled drum. The drum limit, plate measurement and plate configuration may differ. Keeping in mind the end goal to build the limit of the Spheronization arrange, a persistently working Spheronizer has been presented. The procedure produces items going from scarcely formed, sporadic particles, to exceptionally round particles with radically extraordinary properties. Adjusting the organization, the pulverizing liquid or the procedure conditions, can modify tableting qualities. The principle preferred standpoint of delivering drug-stacked circles or pellets is the ability to create round pellets of a uniform size and high medication content up to $90 \%$. As of late, extraordinary sorts of fluidized bed rotating processors have been created more Effectively to prepare compaction-sort pellets, for example, the expulsion Spheronization process in a oneadvance process. This system has tackled numerous issues identified with the multi-step expulsion and Spheronization process.

\section{MATERIALS}

Ivabradine Hydrochloride received form Astron Research Center, Ahmedabad as a gift sample. Microcrystalline cellulose, Lactose, PVPK 30, Colloidal Silicone Dioxide, Talc and Triethyl Citrate purchased from S.D. Fine chemicals, Ahmedabad. Methacrylic acid and Kollicoat SR 30 D received from Olcare Laboratory, Mumbai.

\section{METHODS 5, 6,7}

\section{Pre-formulation study}

\section{Organoleptic Characteristics}

Colour and odour of Ivabradine Hydrochloride were characterized and recorded using descriptive terminology.

\section{Flow Properties}

\section{Bulk density (BD)}

Weigh accurately $1 \mathrm{~g}$ of drug (M), which was previously passed through 20 \# sieve and transferred in $10 \mathrm{ml}$ graduated cylinder. Carefully level the powder without compacting and read the unsettled apparent volume $\left(\mathrm{V}_{0}\right)$. Calculate the apparent bulk density in $\mathrm{gm} / \mathrm{ml}$ by the following formula:

$$
\text { Bulk density = weight of powder / Bulk volume }
$$

\section{Tapped density (TD)}

Weigh accurately $1 \mathrm{~g}$ of drug, which was previously passed through 20 \# sieve and transfer in $10 \mathrm{ml}$ graduated cylinder. Then manually tap the cylinder from the fixed height. Tap the cylinder for 100 times and measure the tapped volume $\left(V_{1}\right)$ Calculate the tapped bulk density in $\mathrm{gm} / \mathrm{ml}$ by the following formula:

Tapped density = weight of powder / Tapped volume

\section{Carr's index}

The Compressibility Index of the powder blend was determined by Carr's compressibility index. It is a simple test to evaluate the BD and TD of a powder and the rate at which it packed down. The formula for Carr's Index is as below:

$$
\text { Carr's index }(\%)=[(T D-B D) \times 100] / T D
$$

\section{Hausner's ratio}

The Hausner's ratio is a number that is correlated to the flow ability of a powder or granular material.

$$
\text { Hausner's ratio }=T D / B D
$$

\section{Angle of repose}

The angle of repose of API powder was determined by the funnel method. The accurately weight powder blend were taken in the funnel. The height of the funnel was adjusted in such a way the tip of the funnel just touched the apex of the powder blend. The powder blend was allowed to flow through the funnel freely on to the surface. The diameter of the powder cone was measured and angle of repose was calculated using the following equation.

$$
\tan \phi=h / r
$$

Where, $h$ and $r$ are the height and radius of the powder cone respectively.

\section{Solubility studies}

The solubility of the drug in distilled water, $0.1 \mathrm{~N} \mathrm{HCl}$ and buffer solutions was determined by phase equilibrium method. An excess amount of drug was taken into the 50 $\mathrm{ml}$ conical flasks containing $20 \mathrm{ml}$ of distilled water. Conical flasks were closed with aluminium foil and constantly agitated at room temperature for $24 \mathrm{hr}$, using rotary shaker. After $24 \mathrm{hr}$, the solution was filtered through filter paper. The amount of drug solubilised was then estimated by spectrophotometrically.

\section{Melting point determination}

Melting point determination of the drug sample was done by open capillary method. Drug was taken in glass capillary whose one end was sealed by flame. The capillary 
containing drug was dipped in liquid paraffin inside the melting point apparatus. Melting point was the first indication of purity of the sample since the presence of relatively small amount of impurity can be detected by a lowering as well as widening in the melting point range.

\section{Preparation of calibration curve of Ivabradine $\mathbf{H C l}{ }^{8,9}$}

\section{Standard solution}

Ivabradine hydrochloride, $100 \mathrm{mg}$ was weighed accurately and transferred into the $100 \mathrm{~mL}$ standard flask. A small amount of $\mathrm{pH} .6 .8$ phosphate buffer was added to dissolve the drug. The volume was made up to $100 \mathrm{~mL}$ with buffer.

\section{Working standard solution}

From the above standard solution, $10 \mu \mathrm{g} / \mathrm{mL}$ concentration was prepared by diluting with $\mathrm{pH} 6.8$ phosphate buffer.

\section{Scanning of absorption maxima}

Working standard solution of $10 \mu \mathrm{g} / \mathrm{ml}$ of Ivabradine hydrochloride was scanned in the wavelength range of 200-400 $\mathrm{nm}$ against the reagent blank to obtain the absorption maxima using UV-visible Spectrophotometer (Shimadzu).

\section{Construction of calibration curve}

Standard solution of Ivabradine hydrochloride was diluted with phosphate buffer to get dilutions containing 10, 20, 30,40 and $50 \mu \mathrm{g} / \mathrm{ml}$ of Ivabradine hydrochloride. The absorbencies of these diluted solutions were measured using at $286 \mathrm{~nm}$ against reagent blank. Each sample was estimated in triplicate, and the average values reported. Same method was followed by using $0.1 \mathrm{~N} \mathrm{HCl}(\mathrm{pH} 1.2)$ as a solvent.

\section{Drug - Excipients compatibility studies}

To investigate any possible interactions between the drug and Excipients used, the FT-IR spectra of pure drug and its physical mixture with different Excipients/final formulation mixture were carried out using FTIR spectrophotometer. The samples were prepared as $\mathrm{KBr}$ (potassium bromide) disks compressed under a pressure of $150 \mathrm{lbs}$. The wave number range is selected in between $400-4000 \mathrm{~cm}^{-1}$.

\section{Dose Calculation}

The pharmacokinetic parameters of Ivabradine $\mathrm{HCl}$ were utilized for the calculation of theoretical drug release profile for $12 \mathrm{hrs}$ dosage form.

The total dose of Ivabradine $\mathrm{HCl}$ required for $12 \mathrm{hrs}$ release profile was calculated using following equation.

$$
\begin{aligned}
\text { Total Dose }=\text { Loading } & \text { Dose }\left\{1+\left(0.693 \times \mathrm{t} / \mathrm{t}_{1 / 2}\right)\right\} \\
& =5\{1+(0.693 \times 12 / 2)\} \\
& =25.79 \mathrm{mg} \sim 25.8 \mathrm{mg}
\end{aligned}
$$

Where,

$t$ is time up to which controlled release is required and $t 1 / 2$ is half-life of drug.

\section{Preparation of Pellets}

\section{Preparation of drug containing pellets}

Extended-release pellets of Ivabradine $\mathrm{HCl}$ were prepared by wet granulation technique using Microcrystalline Cellulose and Lactose were passed through the 40 \# sieve and mix till uniform mixing obtained. PVPK 30 was passed through 40\# sieve and dissolved in a sufficient quantity of purified water using continuous stirring with mechanical stirrer, till thick transparent paste was obtained. Now dry blend was granulated using previously made solution and add extra water if necessary. Above wet mass was transfer in to extruder and collect road shape extrudes. Now above extruded product was transfer in to spheronizer and continuous observed it and collects it after perfect round shape was obtained. It would be taken time for Approximately $10 \mathrm{~min}$. Sprinkle extra talc for reducing clumping formation or reduce the static charges between

\begin{tabular}{|c|c|c|c|c|c|c|}
\hline Material & FUNCTION & A1 & A2 & A3 & A4 & A5 \\
\hline Ivabradine $\mathrm{HCl}$ & Drug & $50 \%$ & $50 \%$ & $50 \%$ & $50 \%$ & $50 \%$ \\
\hline MCC & Spheronizing Agent & $22.5 \%$ & $10 \%$ & $35 \%$ & $23.5 \%$ & $21.5 \%$ \\
\hline Lactose & Filler & $22.5 \%$ & $35 \%$ & $10 \%$ & $23.5 \%$ & $21.5 \%$ \\
\hline PVP K 30 & Binder & $5 \%$ & $5 \%$ & $5 \%$ & $3 \%$ & $7 \%$ \\
\hline Water & Vehicle & q.s & q.s & q.s & q.s & q.s \\
\hline \multicolumn{2}{|c|}{ Total } & $100 \%$ & $100 \%$ & $100 \%$ & $100 \%$ & $100 \%$ \\
\hline
\end{tabular}
pellets.

Table 1: Trial batch of Pellets preparation

\section{Barrier Coating on Pellets}

Prepared pellets were taken for barrier coating in coating machine. $5 \%$ PVPK 30 solution prepared in water and sprayed on pellets up to $1 \%$ weight gain. Coating Parameters are given below table 2 .

\section{Polymer Coating}

Barrier coated pellets were taken for polymer coating. Polymer coating were done for drug release control. Here Kollicoat SR 30 D was taken as rate controlling polymer. Kollicoat SR 30 D, 30 \% ready dispersion taken and diluted with water as per requirement. Talc added as tacking agent 
under continuous stirring. At the end triethyl citrate added as plastisizer and stirred for $30 \mathrm{~min}$ before use.

\section{Enteric Coating}

Polymer coated pellets were taken for barrier coating as per 5.7.3 step.Then finally enteric coating was done on pellets using Eudragit L30D-55 enteric coated polymer up to $5 \%$ weight gain.

\section{Preparation of Coating Solution}

First of all, Talc and Aerosil was sifted through 40\# sieve. Mixed both excipients and homogenize using water in till very fine particles in solution were obtained. Now collect it and mixed with Eudragit L30D-55 polymer dispersion using mechanical stirrer for the continuous stirring, which help to prevent settlement of talc at the bottom of the mixing tank. Above solution was sifted through the 100 \# sieve and used for the coating on the previously prepared pellets.

\section{Enteric Coating of Pellets in Coater}

- Pellets were loaded in coating pan.

- Coating of pellets done by using $1.2 \mathrm{~mm}$ Nozzle gun.

- Following are the coating parameters;
Table 2: Preliminary Trials for Process Parameters

Preliminary Trials for Die hole size on batch A1

\begin{tabular}{|c|c|}
\hline BATCH & DIE HOLE SIZE \\
\hline D1 & $0.5 \mathrm{~mm}$ \\
\hline D2 & $1.0 \mathrm{~mm}$ \\
\hline D3 & $1.5 \mathrm{~mm}$ \\
\hline
\end{tabular}

Preliminary Trials for spheronization speed on batch A1

\begin{tabular}{l|c|}
\hline S1 & 600 \\
\hline S2 & 1000 \\
\hline S3 & 1300
\end{tabular}

Preliminary Trials for Spheronization time on batch A1

\begin{tabular}{|c|c|}
\hline T1 & $\mathbf{1}$ to $5 \mathrm{~min}$ \\
\hline T2 & $\mathbf{8}$ to $\mathbf{1 2} \mathbf{~ m i n}$ \\
\hline T3 & $12018 \mathrm{~min}$ \\
\hline
\end{tabular}

Coating parameters for Barrier coating.

\begin{tabular}{c|c|}
\hline Parameters & Value \\
\hline Pan & $8.5 \mathrm{inch}$ \\
\hline Gun & $1.0 \mathrm{~mm}$ \\
\hline
\end{tabular}

Inlet Air Temp. $\quad 40^{\circ} \mathrm{C}$

Inlet Air Flow 20-40 cfm

Pan rpm 5-8 rpm

Atomization Air Pressure 1.0-1.5 atm

Spray rate $\quad 3-5 \mathrm{gm} / \mathrm{min}$

Table 3: Optimization of polymer coating on pellets

\begin{tabular}{|c|c|c|c|c|c|c|c|c|c|}
\hline Formulation & F1 & F2 & F3 & F4 & F5 & F6 & F7 & F8 & F9 \\
\hline Ivabradine $\mathrm{HCl}$ & $50 \%$ & $50 \%$ & $50 \%$ & $50 \%$ & $50 \%$ & $50 \%$ & $50 \%$ & $50 \%$ & $50 \%$ \\
\hline MCC & $22.5 \%$ & $22.5 \%$ & $22.5 \%$ & $22.5 \%$ & $22.5 \%$ & $22.5 \%$ & $22.5 \%$ & $22.5 \%$ & $22.5 \%$ \\
\hline Lactose & $22.5 \%$ & $22.5 \%$ & $22.5 \%$ & $22.5 \%$ & $22.5 \%$ & $22.5 \%$ & $22.5 \%$ & $22.5 \%$ & $22.5 \%$ \\
\hline PVP K 30 & $5 \%$ & $5 \%$ & $5 \%$ & $5 \%$ & $5 \%$ & $5 \%$ & $5 \%$ & $5 \%$ & $5 \%$ \\
\hline Water & q.s & q.s & q.s & q.s & q.s & q.s & q.s & q.s & q.s \\
\hline \% Polymer coating & $2 \%$ & $4 \%$ & $6 \%$ & $8 \%$ & $10 \%$ & $12 \%$ & $14 \%$ & $16 \%$ & $20 \%$ \\
\hline
\end{tabular}

\section{Evaluation of Pellets}

\section{Physical Description}

Pellets shape observed by visual observation.

\section{Bulk Density}

Bulk density = Weight of powder / Volume

\section{Tapped density}

Tapped density = Weight of powder / Tapped volume

\section{Carr's index (\%)}

It is one of the most important parameter to characteristic the nature of powders and granules. It can be calculated from the following equation-
Carr's index = Tapped density - Bulk density / Tapped density $X 100$

\section{Hausner's ratio}

Hausner's ratio is an important character to determine the flow property of powder and granules. This can be calculation by the following formula-

Value $<1.25$ indicate good flow (=20\% Carr)

While $>1.50$ indicate poor flow $(=35 \%$ Carr)

Hausner's ratio $=$ Tapped density / Bulk density

\section{Drug Content}

One hundred milligrams of pellets were dissolved in $100 \mathrm{ml}$ of 6.8 phosphate buffer. The resulting solution was analyzed spectrophotometrically at $301 \mathrm{~nm}$. 


\section{In-vitro dissolution profile}

Dissolution studies for each formulation were performed in a calibrated 8 station dissolution test apparatus equipped with paddles (USP apparatus II method)

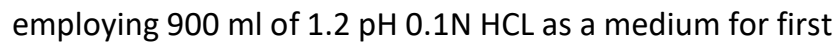
two hours and in $6.8 \mathrm{pH}$ phosphate buffer for next 2 hours than in 7.4 phosphate buffer as a medium upto 12 hours. The paddles were operated at $50 \mathrm{rpm}$ and the temperature was maintained at $37 \pm 0.5^{\circ} \mathrm{C}$ throughout the experiment. Samples were withdrawn at regular intervals up to 12 hours and replaced with equal volume of dissolution medium to maintain the constant volume throughout the experiment. Samples withdrawn at various time intervals were suitably diluted with same dissolution medium and the amount of drug released was estimated by an ultraviolet visible spectrophotometer at $301 \mathrm{~nm}$.

\section{Drug release kinetic study}

Data obtained form in vitro drug release studies were fitted to disso calculation software. The kinetic models used are zero order, first order, Korshmers and papps, Hexon crowell, and Higuchi equation.

The rate and mechanism of release were analyzed by fitting the dissolution data into the zero-order equation:

$$
\mathrm{Q}=\mathrm{kOt}
$$

Where, $Q$ is the amount of drug released at time $t, k 0$ is the release rate constant. The dissolution data fitted to the first order equation:

$$
\ln (100-Q)=\ln 100-K 1 \mathrm{t}
$$

Where, $\mathrm{k} 1$ is the release rate constant. The dissolution data was fitted to the Higuchi's equation:

$$
\mathrm{Q}=\mathrm{k} 2 \mathrm{t} 1 / 2
$$

Where, $\mathrm{k} 2$ is the diffusion rate constant.

The dissolution data was also fitted to Korsmeyer equation, which is often used to describe the drug release behavior from polymeric systems:

$$
\log (M t / M \infty)=\log k+n \log t
$$

Where $\mathrm{Mt}$ is the amount of drug released at time $t, \mathrm{M}_{\infty}$ is the amount of drug release after infinite time, $\mathrm{K}$ is a release rate constant incorporating structural and geometric characteristics of the tablet, $\mathrm{n}$ is the diffusion exponent indicative of the mechanism of drug release.

If $n=0.45$ the release is Fickian diffusion, if $n>0.45$ the release is non Fickian diffusion.

\section{Stability studies}

Optimized formulation was stored at elevated temperatures such as $40{ }^{\circ} \mathrm{C} \pm 2{ }^{\circ} \mathrm{C} / 75 \% \pm 5 \% \mathrm{RH}$ for 30 days. The samples were withdrawn at intervals of 30 days and checked for physical changes as well as drug content and drug release.

\section{RESULTS AND DISCUSSION}

\begin{tabular}{|c|c|c|c|}
\hline Sr. No. & \multicolumn{2}{|c|}{ Characteristic Properties } & Observation/Result \\
\hline \multirow{2}{*}{1} & \multirow{2}{*}{$\begin{array}{l}\text { Organoleptic } \\
\text { Characteristics }\end{array}$} & Colour & White to slightly yellow powder \\
\hline & & Odour & Odorless \\
\hline \multirow{5}{*}{2} & \multirow{5}{*}{ Flow Properties } & Bulk density (g/ml) & $0.24 \pm 0.03$ \\
\hline & & Tapped density (g/ml) & $0.45 \pm 0.02$ \\
\hline & & Carr's index (\%) & $46.66 \pm 0.09$ \\
\hline & & Hausner's ratio & $1.87 \pm 0.05$ \\
\hline & & Angle of repose $\left(\vartheta^{\circ}\right)$ & $43^{\circ} \pm 2^{\circ}$ \\
\hline 3 & Melting Point & By Capillary Method & $196.0^{\circ} \mathrm{C}$ \\
\hline \multirow{3}{*}{4} & \multirow{3}{*}{ Solubility } & Water & Soluble ( $8.5 \mathrm{mg} / \mathrm{ml})$ \\
\hline & & $p H 1.2,0.1 \mathrm{~N} \mathrm{HCl}$ & Soluble $(1.9 \mathrm{mg} / \mathrm{ml})$ \\
\hline & & pH 6.8 Phosphate Buffer & Soluble (7.9 mg/ml) \\
\hline
\end{tabular}

\section{Pre-formulation Studies}

Characterization of Drug

Table 4: Characteristic Properties of Ivabradine $\mathrm{HCl}$

Based on above physical characterization of API it concluded that the API has a poor flow in nature. Further, Melting point of drug found to be $196.0{ }^{\circ} \mathrm{C}$ which was complies with the melting range of the drug from literature. Solubility of drug found satisfactory in water as well as acidic and basic buffer media, hence solubility enhancement is not required.

\section{Optimization of Process Parameters}

Optimum Die hole size was needed for proper size of pellets formulation. Machine Provided variable dies hole sizes ranging between $0.5,1,1.5$ and $2 \mathrm{~mm}$ at $0.5 \mathrm{~mm}$ (D1) friable small pellets were obtained and at $1.5 \mathrm{~mm}$ (D3) big regular shaped pellets were obtained at $1 \mathrm{~mm}$ (D2) average $1 \mathrm{~mm}$ spherical pellets were obtained so it was selected for further study. 
Table 5: Optimization of Process Parameters

\begin{tabular}{|c|c|c|}
\hline \multicolumn{3}{|c|}{ Results of Preliminary Trials for Die hole size } \\
\hline BATCH & DIE HOLE SIZE & INFERANCE \\
\hline D1 & $0.5 \mathrm{~mm}$ & Friable small pellets \\
\hline D2 & $1.0 \mathrm{~mm}$ & $\begin{array}{l}\text { Average } 1 \mathrm{~mm} \\
\text { spherical pellets }\end{array}$ \\
\hline D3 & $1.5 \mathrm{~mm}$ & $\begin{array}{l}\text { Big regular shaped } \\
\text { pellets }\end{array}$ \\
\hline \multicolumn{3}{|c|}{ Result of Preliminary Trials of Spheronization speed } \\
\hline S1 & 600 & Long extrudates \\
\hline S2 & 1000 & Spherical pellets \\
\hline S3 & 1300 & Broken particles \\
\hline \multicolumn{3}{|c|}{ Results of Preliminary Trials for Spheronization Time } \\
\hline $\mathrm{T} 1$ & 1 to $5 \mathrm{~min}$ & Extrudates \\
\hline T2 & 8 to $12 \mathrm{~min}$ & Pellets \\
\hline T3 & 12 to $18 \mathrm{~min}$ & Broken pellets \\
\hline
\end{tabular}

Spheronization speed was optimized for proper spherical shape of pellets formation. Variable spheronization speed was available between 600-1800 rpm available. At $600 \mathrm{rpm}$ (S1) long extrudates were obtained and at 1200rpm (S3) pellets were broken. At 1000rpm (S2) spherical shape pellets were obtained so it was selected for further pellet preparation. Spheronization time is optimized for proper shape of pellets at 1 to 5 minutes (T1) Extrudates were obtained and at 15 to 20 minutes (T3) pellets was broken at a 8 to 12 minutes (T2) spherical shape pellets were obtained so it was further study for pellet formation.

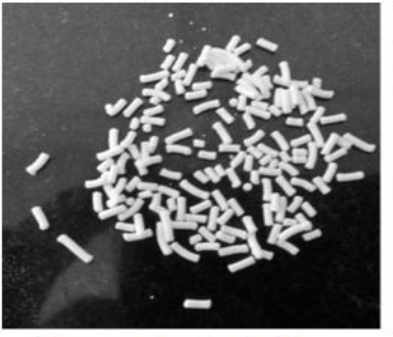

Long extrudates at $2 \mathrm{~min}$

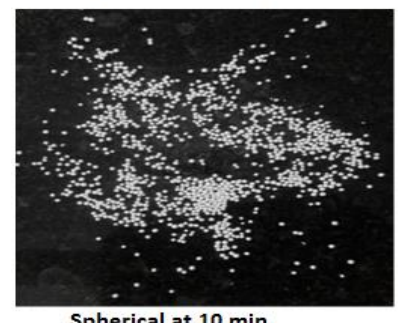

Spherical at $10 \mathrm{~min}$

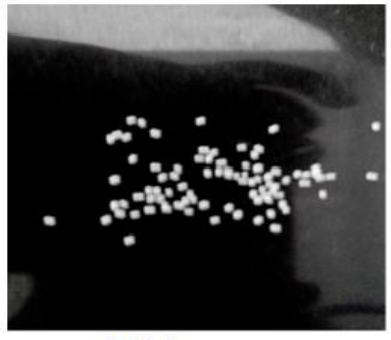

At $5 \mathrm{~min}$

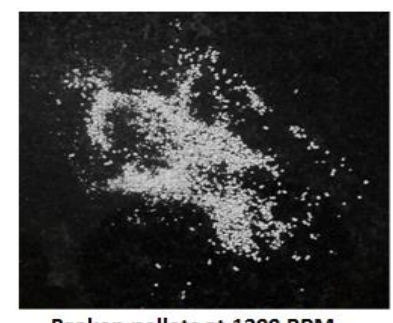

Broken pellets at 1200 RPM
Figure 1: Spherical pellet parameter optimization

\section{Evaluation of Pellets}

\section{Micromeritic Properties of Pellets}

Evaluations of enteric coated pellets were carried out for flow properties. The flow properties of pellets were most important parameter for filling pellets into the capsule shell. The angle of repose values ranges from. $21.65 \pm 0.30$ to $24.73 \pm 0.34$ the bulk density and tapped density ranges from $0.72 \pm 0.005$ to $0.82 \pm 0.004\left(\mathrm{gm} / \mathrm{cm}^{3}\right)$ and $0.78 \pm$ 0.003 to $0.90 \pm 0.006\left(\mathrm{gm} / \mathrm{cm}^{3}\right)$ respectively. The values of angle of repose, Carr's index and Hausnar's ratio indicate excellent flow properties of pellets. Formulation F1-F9 evaluated for their flow properties and data recorded in below table 6 . From the results it concluded that all the formulation having good flow properties. Further it will help during pellets filling if any.

Table 6: Micromeritic Properties of Pellets

\begin{tabular}{|c|c|c|c|c|c|}
\hline Batch & $\begin{array}{l}\text { Angle of } \\
\text { repose }(\theta)\end{array}$ & $\begin{array}{l}\text { Bulk density } \\
(\mathrm{gm} / \mathrm{ml})\end{array}$ & $\begin{array}{l}\text { Tapped density } \\
(\mathrm{gm} / \mathrm{ml})\end{array}$ & Carr's index (\%) & $\begin{array}{l}\text { Hausner's } \\
\text { ratio }\end{array}$ \\
\hline F1 & $23.43 \pm 0.42$ & $0.80 \pm 0.004$ & $0.85 \pm 0.003$ & $4.86 \pm 0.15$ & $1.05 \pm 0.001$ \\
\hline $\mathrm{F} 2$ & $21.13 \pm 0.28$ & $0.74 \pm 0.004$ & $0.78 \pm 0.003$ & $4.98 \pm 0.27$ & $1.04 \pm 0.001$ \\
\hline F3 & $22.97 \pm 1.09$ & $0.82 \pm 0.004$ & $0.85 \pm 0.002$ & $2.82 \pm 0.69$ & $1.02 \pm 0.003$ \\
\hline F4 & $24.73 \pm 0.34$ & $0.81 \pm 0.004$ & $0.90 \pm 0.006$ & $9.12 \pm 0.42$ & $1.10 \pm 0.004$ \\
\hline F5 & $22.39 \pm 0.56$ & $0.82 \pm 0.004$ & $0.87 \pm 0.009$ & $4.80 \pm 0.72$ & $1.05 \pm 0.006$ \\
\hline F6 & $21.65 \pm 0.30$ & $0.78 \pm 0.009$ & $0.88 \pm 0.001$ & $5.81 \pm 0.49$ & $1.06 \pm 0.005$ \\
\hline F7 & $22.19 \pm 0.31$ & $0.74 \pm 0.003$ & $0.86 \pm 0.004$ & $12.95 \pm 0.47$ & $1.14 \pm 0.004$ \\
\hline F8 & $21.69 \pm 0.30$ & $0.72 \pm 0.005$ & $0.80 \pm 0.007$ & $09.01 \pm 0.42$ & $1.10 \pm 0.004$ \\
\hline F9 & $22.13 \pm 0.28$ & $0.75 \pm 0.003$ & $0.83 \pm 0.004$ & $8.93 \pm 0.32$ & $1.09 \pm 0.203$ \\
\hline
\end{tabular}

\section{Evaluation of Pellets for Drug Content}

Formulation F1-F9 checked for Drug Content and results recorded in below table 6.5. All formulations were found within the limit. It means drug was distributed equally in properly in the formulation.

\section{Evaluation of Pellets for Drug Release Study}

Drug release study of enteric coated pellets carried out in $0.1 \mathrm{~N} \mathrm{HCL}$ for first 2 hours. In first 2 hours it seen that the enteric coating was sufficient to remain stable in acidic $\mathrm{pH}$. No drug release observed from F1-F9 in first $2 \mathrm{hr}$ in all formulation. So it can concluded that the $5 \%$ Eudragit 
L30D-55 Enteric coating was sufficient to prevent the drug loaded sustained release pellets from acidic $\mathrm{pH}$. Further when the pellets were checked in alkaline $\mathrm{pH}$ after $2 \mathrm{hr}$ the drug release was started. Here Kollicoat SR 30 D was taken to control the drug release. From $3 \mathrm{hr}$ onwards we can see the drug release in pellets. F1 gives maximum $54 \%$ drug release in four hour. Further the \% of polymer coating increase in $\mathrm{F} 1$ to $\mathrm{F} 9$ side, \% drug release is decrease in 4 hour. So enteric coat was break in alkaline $\mathrm{pH}$. F1-F9 shows drug release more than $10 \%$ in $3^{\text {rd }}$ hours. Also release was continuing in 4 th hours. And more than $20 \%$ drug release after 4 hour. One more important thing is that bursting effect was not seen in any formulation. Further the effect of Kollicoat SR 30 D seen in formulation. $2 \%$ coating F1 batch release drug in $9 \mathrm{hr}$. F2 gives up to 10 hours and F3 gives up to 11 hours and increase in \% Coating should retard the drug release. F6 batch which have $12 \%$ polymer coating release $99.9 \%$ drug release in $12 \mathrm{hr}$. this is the batch into which our objectives achieved. Further more than $12 \%$ polymer coating batch release less than $95 \%$ drug in $12 \mathrm{hr}$. F7-F9 batch in which amount of polymer coating is more than $12 \%$ retard the drug release and no achieved up to $90 \%$ in 12 hour. So we can conclude that the $12 \%$ polymer coating was sufficient to release the drug up to 12 hours.

Table 7: \% Drug release of F1-F9

\begin{tabular}{|c|c|c|c|c|c|c|c|c|c|}
\hline Time (Hr) & F1 & F2 & F3 & F4 & F5 & F6 & F7 & F 8 & F9 \\
\hline 1 & 0 & 0 & 0 & 0 & 0 & 0 & 0 & 0 & 0 \\
\hline 2 & 1.05 & 1.45 & 0.98 & 1.32 & 2.03 & 1.06 & 0.89 & 2.15 & 1.87 \\
\hline 3 & 35.40 & 25.10 & 21.78 & 23.97 & 11.90 & 13.58 & 18.74 & 14.78 & 10.40 \\
\hline 4 & 54.60 & 34.90 & 31.41 & 27.69 & 21.63 & 25.51 & 33.59 & 20.40 & 18.60 \\
\hline 5 & 69.70 & 55.90 & 42.98 & 31.81 & 35.24 & 38.87 & 43.94 & 25.54 & 26.90 \\
\hline 6 & 81.40 & 68.41 & 51.87 & 41.71 & 42.67 & 48.98 & 48.81 & 30.83 & 28.40 \\
\hline 7 & 89.90 & 75.60 & 65.90 & 47.01 & 48.81 & 56.58 & 54.40 & 35.08 & 32.50 \\
\hline 8 & 94.50 & 86.40 & 75.80 & 53.47 & 52.89 & 64.10 & 59.66 & 44.98 & 42.90 \\
\hline 9 & 99.90 & 91.60 & 85.90 & 62.00 & 57.66 & 72.60 & 61.40 & 48.94 & 52.60 \\
\hline 10 & 99.90 & 95.80 & 90.40 & 78.34 & 63.79 & 80.90 & 73.29 & 55.07 & 60.40 \\
\hline 11 & 99.90 & 99.80 & 99.80 & 86.53 & 73.35 & 83.80 & 88.48 & 62.21 & 71.80 \\
\hline 12 & 99.90 & 99.90 & 99.90 & 93.60 & 92.13 & 99.80 & 94.50 & 88.60 & 84.60 \\
\hline
\end{tabular}

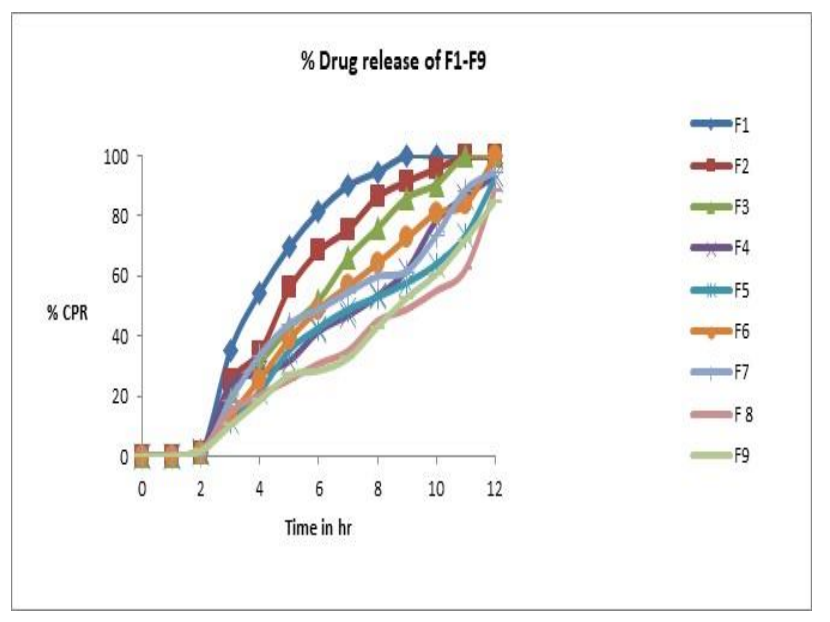

Figure 2: \% Drug release of F1-F9

\section{CONCLUSION}

In the present study, a novel extrusion-spheronization method employed to prepare pellets of Ivabradine $\mathrm{HCl}$ using various carrier materials to load the drug into pellets. Microcrystalline cellulose incorporated in formulation via extruder-spheronization to enhance the rheological properties of the wetted mass, resulted in good sphericity, low friability, high density, and smooth surface for successful extrusion and spheronization. Pellets are prepared using extrusion-spheronization and the process parameters are optimized. $1.0 \mathrm{~mm}$ die hole size, $1000 \mathrm{rpm}$ spheronization speed and 8-12 min spheronization time was optimized for further study in core pellets. Polymer coating done with Kollicoat SR 30 D as rate controlling polymer and finally enteric coating done with Eudragit L30D-55.Prepared enteric coated pellets were checked for flow properties. It found that all formulation has a Hausner's ratio below 1.2, so all formulation has good flow properties. Formulation F1-F9 passed the friability test, so mechanical strength was also good in all batches of enteric coated pellets. Drug content found within limit. Drug distributed properly in all batches.Drug release in formulation F1-F9 studied and it found that the low polymer concentration ( $2 \%$ ) was unable to retard the drug release up to $12 \mathrm{hr}$ so concentration increased batch by batch and finally $12 \%$ coating batch gives desired results which retard the drug release up to $12 \mathrm{hr}$. also found that the drug release was very low after more \% coating than the $12 \%$. Hence based on that the F5 batch was optimized batch and its found stable during stability study of 1 month.

Acknowledgment: The Author and co-author, thanks to Saraswati Institute of Pharmaceutical Sciences, for providing the necessary facility to accomplish the work we 
also humble gratitude to our colleague and non-teaching staff for their support during the work.

\section{REFERENCES}

1. Patel H, Gohel M. A review on Enteric coated pellets composed of core pellets prepared by extrusionspheronization. Recent Pat Drug Deliv Formul. 2019; 13(2): 83-90.

2. Bölcskei É, Regdon G Jr, Sovány T, Ghanam D, Knop K, Kleinebudde $P$, et al. Preparing of pellets by extrusion/spheronization using different types of equipment and process conditions. Drug Dev Ind Pharm. 2014; 40(6): 762-4.

3. Prinesh N, Roshan M, Kalariya PD, Rahul P, Abhay $T$, Gananadhamu Sand Srinivas R. Characterization of degradation products of Ivabradine by LC-HR-MS/MS: a typical case of exhibition of different degradation behavior in $\mathrm{HCl}$ and $\mathrm{H} 2 \mathrm{SO} 4$ acid hydrolysis". J Mass Spectrom. 2015; 50: 344-353.

4. Irfan A, Sachin B, Avinash C. Gaurav S, "Formulation and Evaluation of sustained release pellets of
Zidovudine by using Extrusion and Spheronization Technique. "Asian J Res Pharm Sci. 2020; 10(4): 241247.

5. Vanitha K, Venkataswamy M, Niharika S, Ramesh A. Formulation Development and Evaluation of Mebeverine extended release Pellets. Asian J Pharm Technol. 2018; 8(2): 71.

6. Corlanor [Internet]. Rxlist.com. [cited 2021 Jun 1]. Available from: https://www.rxlist.com/corlanordrug.htm

7. Ivabradine Tablets [Internet]. Drugs.com. [cited 2021 Jun 1]. Available from: https://www.drugs.com/cdi/ivabradine-tablets.html

8. PubChem. Ivabradine [Internet]. Nih.gov. [cited 2021 Jun 1]. Available from: https://pubchem.ncbi.nlm.nih.gov/compound/Ivabra dine

9. Drugbank.ca. [cited 2021 Jun 1]. Available from: https://www.drugbank.ca/drugs/DB09083.

Source of Support: The author(s) received no financial support for the research, authorship, and/or publication of this article.

Conflict of Interest: The author(s) declared no potential conflicts of interest with respect to the research, authorship, and/or publication of this article.

For any question relates to this article, please reach us at: editor@globalresearchonline.net New manuscripts for publication can be submitted at: submit@globalresearchonline.net and submit_ijpsrr@rediffmail.com 